\title{
The Significance of Cardiac Sympathetic Nervous System Abnormality in the Long-Term Prognosis of Patients with a History of Ventricular Tachyarrhythmia
}

\author{
Yasushi Akutsu ${ }^{1}$, Kyouichi Kaneko ${ }^{1}$, Yusuke Kodama ${ }^{1}$, Hui-Ling Li ${ }^{1}$, Mitsuharu Kawamura ${ }^{1}$, Taku Asano ${ }^{1}$, \\ Kaoru Tanno ${ }^{1}$, Akira Shinozuka ${ }^{2}$, Takehiko Gokan ${ }^{2}$, and Youichi Kobayashi ${ }^{1}$ \\ ${ }^{1}$ Division of Cardiology, Department of Medicine, Showa University School of Medicine, Tokyo, Japan; and ${ }^{2}$ Department of \\ Radiology, Showa University School of Medicine, Tokyo, Japan
}

Severe left ventricular dysfunction or cardiac sympathetic nervous system (SNS) abnormality predicts cardiac death in various heart diseases, including arrhythmogenic disorders. However, it is not clear whether SNS abnormality predicts sudden cardiac death during long-term follow-up in patients with a history of ventricular tachyarrhythmia. We hypothesized that SNS abnormality would be associated with recurrent ventricular arrhythmic events.

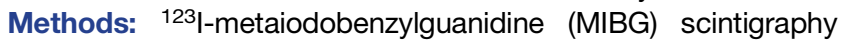
was performed on 86 patients (mean age \pm SD, $46 \pm 19 \mathrm{y}$, $65.1 \% \mathrm{men}$ ) with a history of ventricular tachycardia or fibrillation. 123/-MIBG (111 MBq) was intravenously administered under resting conditions, and planar images were obtained $15 \mathrm{~min}$ and $4 \mathrm{~h}$ later (anterior view for 6 min; $512 \times 512$ matrices; zoom ratio, 1.0). SNS activity was assessed using the heart-to-mediastinum ratio on delayed imaging. Results: During about $11 \mathrm{y}$ of followup (mean \pm SD, $5.2 \pm 3.7$ y), 3 patients (3.5\%) had sudden cardiac death and 21 patients (24.4\%) had sustained ventricular tachyarrhythmic events. SNS abnormality, defined as a heart-tomediastinum ratio of less than 2.8 , and left ventricular dysfunction, defined as a left ventricular ejection fraction of less than $50 \%$, were associated with sudden cardiac death or recurrent ventricular tachyarrhythmic events (18/40 patients [45\%] with SNS abnormality, vs. $6 / 46$ patients [13\%] without, $P=0.004 ; 9 / 15$ patients [60\%] with left ventricular dysfunction, vs. $15 / 71$ patients [21.1\%] without, $P=0.008$ ). After adjustment for potential confounding variables such as age, sex, coronary risk factors, medication use, history of structural heart disease, and left ventricular function, SNS abnormality was a powerful predictor of recurrent arrhythmic events, with a hazard ratio of 3.6 [95\% confidence interval, 1.4-9.2, $P=0.007])$. Further, SNS abnormality had incremental and additive prognostic power in combination with left ventricular dysfunction, with an adjusted hazard ratio of 4.4 [95\% confidence interval, 1.9-9.9, $P<0.0001]$ ). Conclusion: SNS abnormality predicted recurrent ventricular tachyarrhythmic events during long-term follow-up. ${ }^{123}$ I-MIBG scintigraphic evalu-

Received Jun. 16, 2008; revision accepted Sep. 9, 2009.

For correspondence or reprints contact: Yasushi Akutsu, Division of Cardiology, Department of Medicine, Showa University School of Medicine, 1-5-8 Hatanodai, Shinagawaku, Tokyo 142-8666, Japan. E-mail: hzn01233@s02.itscom.net

COPYRIGHT $\odot 2009$ by the Society of Nuclear Medicine, Inc. ations for SNS abnormality may be an option for screening patients at high risk for sudden cardiac death.

Key Words: ventricular tachyarrhythmia; sympathetic nervous system; long-term prognosis; scintigraphy; sudden cardiac death

J Nucl Med 2009; 50:61-67

DOI: 10.2967/jnumed.108.055194

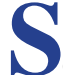

everely depressed left ventricular ejection fraction (LVEF) is a powerful predictor of sudden cardiac death (1-7), and based on the guideline of the American College of Cardiology, American Heart Association, North American Society for Pacing and Electrophysiology, and European Society of Cardiology, prophylactic implantation of a cardioverter defibrillator (ICD) is recommended in patients with ventricular tachycardia (VT) or fibrillation (VF) who have severe left ventricular dysfunction $(3,6)$. Further, patients with ventricular tachyarrhythmia in an apparently normal heart or a heart with slight left ventricular dysfunction but no structural heart disease may also have a high risk of sudden cardiac death $(8,9)$.

An association between autonomic dysfunction and a propensity toward VF during acute myocardial ischemia were first demonstrated in 1982 (10), and impaired autonomic nerve activity has been reported to be a powerful predictor of mortality using heart rate recovery at physical exercise (11), baroreflex sensitivity (12), or ${ }^{123}$ I-metaiodobenzylguanidine (MIBG) scintigraphy (1). The role of cardiac sympathetic nervous system (SNS) abnormality has been demonstrated using ${ }^{123} \mathrm{I}-\mathrm{MIBG}$ scintigraphy in patients with ventricular tachyarrhythmia $(13,14)$, and SNS abnormality has been reported to have significance in several heart diseases, including arrhythmogenic disorder (14-18). We hypothesized that SNS abnormality would be associated with recurrent ventricular arrhythmic events during long-term follow-up. 


\section{MATERIALS AND METHODS}

\section{Study Population}

We studied patients with suspected ventricular tachyarrhythmia who were admitted between December 1994 and February 2007 at Showa University Hospital. The condition of ventricular tachyarrhythmia was diagnosed on the basis of documented VT or VF by ambulance monitoring (usually 3-lead echocardiography), 12-lead electrocardiography, or Holter monitoring. Ventricular tachyarrhythmia was diagnosed as nonsustained VT (3 or more consecutive extrasystoles) or sustained VT or VF (continual VT for at least $30 \mathrm{~s}$ ). ${ }^{123}$ I-MIBG scintigraphy was performed during stable sinus rhythm to assess SNS activity. Structural heart diseases such as ischemic heart disease, dilated or hypertrophic cardiomyopathy, and arrhythmogenic right ventricular dysplasia were diagnosed by echocardiography, myocardial perfusion scintigraphy, coronary angiography, MRI, or left ventricular myocardial biopsy before the ${ }^{123}$ I-MIBG study. Further, patients with ischemic heart disease were reperfused no more than 6 mo before the time of study entry and were confirmed not to have transient and persistent ischemia on stress myocardial perfusion scintigraphy at the time of study entry. A genetic arrhythmogenic disorder such as Brugada syndrome or QT prolongation syndrome was diagnosed by family history, 12-lead electrocardiography at rest and at exercise, or genetic analysis. LVEF was measured by 2-dimensional echocardiography within 1 mo before the ${ }^{123} \mathrm{I}-\mathrm{MIBG}$ study. All patients gave written informed consent before this study, and the protocol was approved by our Institutional Review Board. Prospectively collected data included demographics, existing medical diagnoses, symptoms, risk factors for cardiovascular disease, medications, previous cardiac procedures, and a prior history of cardiac events. Finally, 86 patients (mean age \pm SD, $46 \pm 19 \mathrm{y} ; 65.1 \%$ men) with a history of ventricular tachyarrhythmia (VF, 13 patients; sustained VT, 41 patients; and nonsustained VT, 32 patients) were recruited into this study and were prospectively followed to investigate SNS abnormality as a predictive marker of sudden cardiac death. Of those, 23 patients had a history of structural heart disease ( 7 patients with ischemic heart disease, 11 patients with dilated cardiomyopathy, 4 patients with hypertrophic cardiomyopathy, and 1 patient with arrhythmogenic right ventricular dysplasia) and 9 patients had a genetic arrhythmogenic disorder (1 patient with Brugada syndrome, 1 patient with QT prolongation syndrome, and 7 patients with familial arrhythmia).

\section{${ }^{123}$ |-MIBG Scintigraphic Imaging}

From $1 \mathrm{~d}$ before to $1 \mathrm{~d}$ after the study, $1 \mathrm{mg}$ of potassium iodine was given orally to block thyroid uptake of ${ }^{123}$ I-MIBG. ${ }^{123}$ I-MIBG scintigraphy was performed during sinus rhythm, not tachyarrhythmia. ${ }^{123}$ I-MIBG (111 MBq) was injected intravenously (Dai-ichi Radioisotope Laboratory) and flushed with normal saline solution. Myocardial images were acquired using a standard-field $\gamma$-camera equipped with a medium-energy, parallel-hole collimator (Prism 2000XP; Picker). A 20\% window centered at $159 \mathrm{keV}$ was used. Patients were positioned supine, and anterior-view planar imaging of the chest was performed for $6 \mathrm{~min}$. Identical acquisitions were obtained $15 \mathrm{~min}$ after tracer injection (early images) and $4 \mathrm{~h}$ after tracer injection (delayed images). Images were acquired using $512 \times 512$ matrices and a 1.0 zoom ratio on an Odyssey computer (Philips Co.) for later analysis. Left ventricular MIBG activity was measured using a manually drawn region of interest around the left ventricular myocardium (19). A $20 \times 20$ pixel region of interest was placed over the upper mediastinum. To evaluate the myocardial accumulation of MIBG, we calculated the heart-to-mediastinum (H/M) activity ratio from delayed images obtained $4 \mathrm{~h}$ after injection of the tracer (Fig. 1) (19).

\section{Endpoint}

The mean follow-up time was $5.2 \pm 3.7 \mathrm{y}$, through February 2007 (up to $11.8 \mathrm{y}$ ). The primary endpoint of this study was the occurrence of sustained VT or VF; sudden cardiac death, that is, death within $1 \mathrm{~h}$ after the onset of symptoms in a previously medically stable patient; death during sleep; or unwitnessed death confirmed by dedicated research personnel using a scripted review of the medical record, telephone interview, or record of stored ICD electrograms.

\section{Statistical Analysis}

For descriptive purposes, the patients were divided into 2 groups based on SNS activity at the time of study entry or ventricular arrhythmic events during follow-up. Continuous variables are presented as mean $\pm \mathrm{SD}$. Differences between groups were tested using ANOVA, the post hoc test, or the $\chi^{2}$ test, as appropriate. Further, the Mantel-Haesnzel test was used to investigate whether significant differences remained after adjusting for covariates. Receiver-operating-characteristic analysis was performed to define thresholds for prognostic markers; this analysis provided optimal sensitivity and specificity in predicting longterm prognosis. Thresholds were obtained by minimizing the expression $(1-\text { sensitivity })^{2}+(1-\text { specificity })^{2}(20)$. When considered as a dichotomous variable, SNS abnormality was defined as an H/M ratio of less than 2.8 (Fig. 2). The associations between prognostic markers and mortality were formally tested by construction of the Kaplan-Meier curve (21) and the Cox proportional-hazards model (22). The final multivariate Cox regression model was built by a stepwise procedure. All variables considered to possibly affect arrhythmic events were entered stepwise into a program to analyze for the best possible discrimination between the 2 groups. At each step, a single additional variable was entered into the set of discriminating variables. The first variable (the $\mathrm{H} / \mathrm{M}$ ratio) was the most powerful differentiating dimension, but later variables represented additional significant dimensions of differentiation. The variables entered were selected on the basis of minimizing the overall Wilks $\lambda$, a generalized measure of distance. The statistical analysis was done using SPSS for Windows, version 11 (SPSS Inc.).
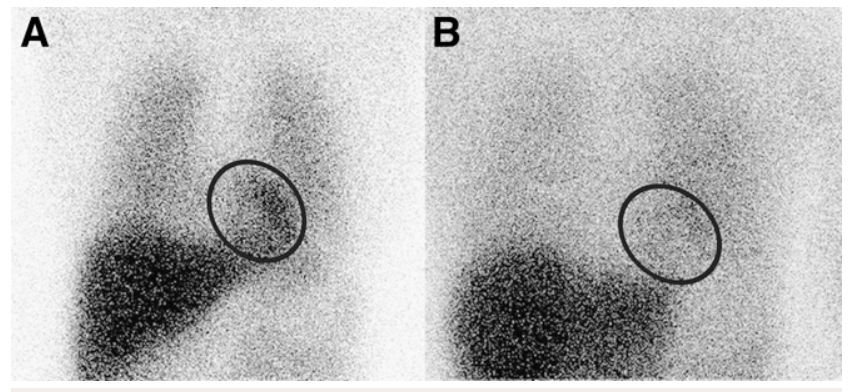

FIGURE 1. Typical cardiac ${ }^{123}$ I-MIBG scintigraphy in patients with normal SNS (A) and abnormal SNS (B). (A) A 39-yold woman with VF who had shown normal SNS activity with $\mathrm{H} / \mathrm{M}$ ratio of 3.5 did not afterward have tachyarrhythmic event. (B) A 34-y-old man with VF who had shown abnormal SNS activity with lower $\mathrm{H} / \mathrm{M}$ ratio of 1.81 then had recurrent tachyarrhythmic event. Ovals indicate region of interest on cardiac area. 


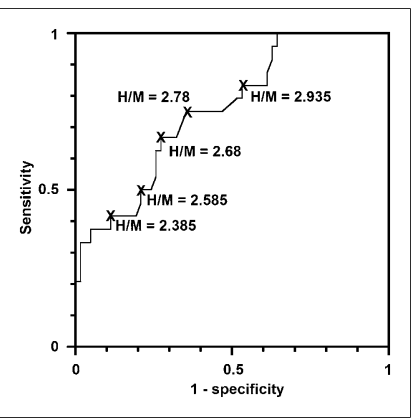

FIGURE 2. Receiveroperator characteristic curve comparing sensitivity and specificity of $\mathrm{H} / \mathrm{M}$ ratio for predicting sudden cardiac death or ventricular tachyarrhythmic events. Optimal thresholds for prediction of $\mathrm{H} / \mathrm{M}$ ratio were 2.78 (sensitivity of 0.75 and specificity of $0.645, P=0.001)$.

\section{RESULTS}

Forty patients had SNS abnormality, defined as an $\mathrm{H} / \mathrm{M}$ ratio of less than 2.8 (Table 1). There were no significant differences in age, sex, history of structural heart disease, or cardiovascular risk factors between patients with and without SNS abnormality. H/M ratio was similar among the various types of ventricular arrhythmia at the time of study entry (VF, $2.6 \pm$ 0.7 ; sustained VT, $2.8 \pm 0.5$; and nonsustained VT, $2.8 \pm 0.7$, $P=$ not significant). The patients with SNS abnormality were more likely to have a history of arrest or syncope than were the patients without SNS abnormality $(P<0.05)$. LVEF was significantly lower in patients with SNS abnormality than in patients without SNS abnormality $(P<0.01)$.
Over 11 y of follow-up, 3 patients had sudden cardiac death $(3.5 \%)$ and 21 patients had sustained ventricular tachyarrhythmic events (24.4\%). Of the 3 patients with sudden cardiac death, 2 had a history of nonsustained VT at the time of study entry, and 1 had a history of sustained VT. One patient with sudden cardiac death had a history of dilated cardiomyopathy with $41 \%$ of LVEF, and he refused ICD. On the other hand, of 13 patients with a history of VF at the time of study entry, 9 received an implanted ICD after study entry, and 7 had recurrent VF during follow-up.

There was no significant difference in age, sex, or coronary risk factors between patients with and without recurrent ventricular arrhythmic events (Table 2). Forty-four patients (51.2\%) had a cardiovascular process (23 patients with structural heart disease, 9 patients with a genetic disorder, and 12 patients with hypertension or diabetes mellitus), and 42 patients did not have a cardiovascular process (idiopathic). The patients with a cardiovascular process were more likely to have arrhythmic events (17 patients [38.6\%] vs. 7 patients [16.7\%], $P=0.023$ ) than were the patients without a cardiovascular process. In particular, a history of structural heart disease was associated with events $(P=0.013)$ (Table 2). Of 11 patients with dilated cardiomyopathy, 7 patients had recurrent ventricular arrhythmic events, including 1 patient with sudden cardiac death. On the other hand, of 4 patients without recurrent arrhythmic events, 1 patient died of brain

TABLE 1. Cardiac SNS Abnormality in Patients with History of Ventricular Tachyarrhythmia

\begin{tabular}{|c|c|c|c|}
\hline \multirow[b]{2}{*}{ Variable } & \multicolumn{2}{|c|}{ SNS activity } & \multirow[b]{2}{*}{$P$} \\
\hline & $\begin{array}{c}\text { Abnormal }(\mathrm{H} / \mathrm{M} \text { ratio }<2.8) \\
(n=40)\end{array}$ & $\begin{array}{c}\text { Normal }(\mathrm{H} / \mathrm{M} \text { ratio } \geq 2.8) \\
(n=46)\end{array}$ & \\
\hline Age (y) & $48 \pm 19$ & $44 \pm 20$ & NS \\
\hline Female & $10(25 \%)$ & $20(43.5 \%)$ & NS \\
\hline VF & $8(20 \%)$ & $5(10.9 \%)$ & NS \\
\hline Sustained VT & $19(47.5 \%)$ & $22(47.8 \%)$ & NS \\
\hline Nonsustained VT & $13(32.5 \%)$ & $19(41.3 \%)$ & NS \\
\hline \multicolumn{4}{|l|}{ Chief complaint } \\
\hline Arrest or syncope & $18(45 \%)$ & $10(21.7 \%)$ & 0.022 \\
\hline Palpitation & $15(37.5 \%)$ & $22(47.8 \%)$ & NS \\
\hline No symptom & $4(10 \%)$ & $8(17.4 \%)$ & NS \\
\hline History of diabetes & $4(10 \%)$ & $4(8.7 \%)$ & NS \\
\hline History of hypertension & $10(25 \%)$ & $8(17.4 \%)$ & NS \\
\hline History of hyperlipidemia & $3(7.5 \%)$ & $4(8.7 \%)$ & NS \\
\hline Structural heart disease & $14(35 \%)$ & $9(19.6 \%)$ & NS \\
\hline Ischemic heart disease & $2(5 \%)$ & $5(10.9 \%)$ & NS \\
\hline Dilated cardiomyopathy & $8(20 \%)$ & $3(6.5 \%)$ & NS \\
\hline Hypertrophic cardiomyopathy & $4(10 \%)$ & 0 & 0.028 \\
\hline Arrhythmogenic right ventricular dysplasia & 0 & $1(2.2 \%)$ & NS \\
\hline Genetic arrhythmogenic disorder & $2(5 \%)$ & 7 (15.2\%) & NS \\
\hline Congestive heart failure & $5(12.5 \%)$ & $2(4.3 \%)$ & NS \\
\hline Positive signal-averaged electrocardiography & $11(27.5 \%)$ & $9(19.6 \%)$ & NS \\
\hline LVEF (\%) & $54.5 \pm 12.4$ & $61.8 \pm 9.4$ & 0.003 \\
\hline Cardiothoracic ratio (\%) & $46 \pm 6.4$ & $45.5 \pm 5.5$ & NS \\
\hline \multicolumn{4}{|c|}{$\begin{array}{l}\text { NS = Not significant. } \\
\text { Positive signal-averaged electrocardiography was defined by guideline of American Heart Association/American College of Cardiology. } \\
\text { ardiothoracic ratio was measured by chest radiography. }\end{array}$} \\
\hline
\end{tabular}


TABLE 2. Long-Term Prognosis in Patients with History of Ventricular Tachyarrhythmia

\begin{tabular}{|c|c|c|c|}
\hline \multirow[b]{2}{*}{ Variable } & \multicolumn{2}{|c|}{$\begin{array}{l}\text { Sudden death or ventricular arrhythmic event } \\
\text { over } 11 \text { y of follow-up }\end{array}$} & \multirow[b]{2}{*}{$P$} \\
\hline & Events $(n=24)$ & No events $(n=62)$ & \\
\hline Age $(y)$ & $51 \pm 18$ & $44 \pm 20$ & NS \\
\hline Female & $7(29.2 \%)$ & $23(37.1 \%)$ & NS \\
\hline VF & $7(29.2 \%)$ & $6(9.7 \%)$ & NS \\
\hline History of diabetes & $3(12.5 \%)$ & $5(8.1 \%)$ & NS \\
\hline History of hypertension & $6(25 \%)$ & $12(19.4 \%)$ & NS \\
\hline History of hyperlipidemia & $2(8.3 \%)$ & $5(8.1 \%)$ & NS \\
\hline Structural heart disease & $11(45.8 \%)$ & $12(19.4 \%)$ & 0.013 \\
\hline Ischemic heart disease & $1(4.2 \%)$ & $6(9.7 \%)$ & NS \\
\hline Dilated cardiomyopathy & $7(29.2 \%)$ & $4(6.5 \%)$ & 0.005 \\
\hline Hypertrophic cardiomyopathy & $2(8.3 \%)$ & $2(3.2 \%)$ & NS \\
\hline Arrhythmogenic right ventricular dysplasia & $1(4.2 \%)$ & 0 & NS \\
\hline Genetic arrhythmogenic disorder & $4(16.7 \%)$ & $5(8.1 \%)$ & NS \\
\hline Congestive heart disease & $4(16.7 \%)$ & $3(4.8 \%)$ & NS \\
\hline $\mathrm{H} / \mathrm{M}$ ratio & $2.3 \pm 0.6$ & $3.0 \pm 0.5$ & $<0.0005$ \\
\hline LVEF (\%) & $53.4 \pm 15.4$ & $60.3 \pm 8.9$ & 0.012 \\
\hline Cardiothoracic ratio (\%) & $47 \pm 6.7$ & $45.2 \pm 5.6$ & NS \\
\hline Use of $\beta$-blocker & $10(41.7 \%)$ & $14(25.6 \%)$ & NS \\
\hline Use of calcium channel antagonist & $3(12.5 \%)$ & $13(21 \%)$ & NS \\
\hline Use of angiotensin-converting enzyme inhibitor & $9(37.5 \%)$ & $14(22.6 \%)$ & NS \\
\hline Use of sodium channel blockers & $3(12.5 \%)$ & $8(12.9 \%)$ & NS \\
\hline Use of amiodarone & $5(20.8 \%)$ & $6(9.7 \%)$ & NS \\
\hline Catheter ablation & $6(25 \%)$ & $19(30.6 \%)$ & NS \\
\hline \multicolumn{4}{|l|}{ NS $=$ not significant. } \\
\hline
\end{tabular}

carcinoma during follow-up, but the other 3 patients survived without heart failure during follow-up.

Antiarrhythmic drugs were started at the time of study entry, after diagnosis of ventricular arrhythmia. Sudden cardiac death or recurrent arrhythmic events occurred during follow-up in 10 of 24 patients $(41.7 \%)$ who were using a $\beta$-blocker, 3 of 11 patients $(27.3 \%)$ who were using sodium channel blockers, and 5 of 11 patients (45.5\%) who were using amiodarone. Antiarrhythmic drugs had been used in 17 of 24 patients (70.8\%) with recurrent tachyarrhythmic events, compared with 24 of 62 patients $(38.7 \%)$ without events $(P<0.01)$, but the patients with a history of structural heart disease had a greater tendency to be using these drugs (17 of 23 patients [73.9\%] with a history of structural heart disease, vs. 24 of 63 patients [38.1\%] without, $P<0.005)$. After adjusting for a history of structural heart disease, we found that the use of antiarrhythmic drugs was not associated with arrhythmic events. An ICD had been implanted in 11 of 17 patients (64.7\%) with recurrent ventricular tachyarrhythmic events during follow-up, but here, too, we found no significant difference after adjusting for a history of structural heart disease.

When considered as a dichotomous variable, SNS abnormality was associated with sudden cardiac death or recurrent ventricular tachyarrhythmic events $(P=0.002)$ (Fig. 3). Left ventricular dysfunction, defined as an LVEF of less than $50 \%$ (the optimal threshold for the prediction based on receiver-operator-characteristic analysis), was also associated with arrhythmic events $(P=0.006)$ (Fig. 4). On univariate Cox proportional-hazards analysis, SNS abnormality, left ventricular dysfunction, or a history of structural heart disease was a powerful predictor of long-term prognosis in each (Table 3). SNS abnormality was associated with arrhythmic events with a hazard ratio of 9.4 (95\% confidence interval, 1.1-74; $P=0.033$ ) even if only patients with structural heart disease were considered. Further, patients with both SNS abnormality and left ventricular dysfunction were more likely to have arrhythmic events than were other patients ( 9 of 12 patients [75\%] vs. 15 of 74 [20.3\%]) (Table 3; Fig. 5). SNS abnormality had incremental and additive prognostic power in combination with left ventricular dysfunction (Table 3). In a multivariate Cox regression

FIGURE 3. Kaplan-Meier survival curves of sudden cardiac death or ventricular tachyarrhythmic eventfree survival according to cardiac SNS abnormality $(\mathrm{H} / \mathrm{M}$ ratio $<2.8)$. Over $11 \mathrm{y}$ of follow-up, SNS abnormality was predictive of sudden cardiac death or ventricular arrhythmic events.

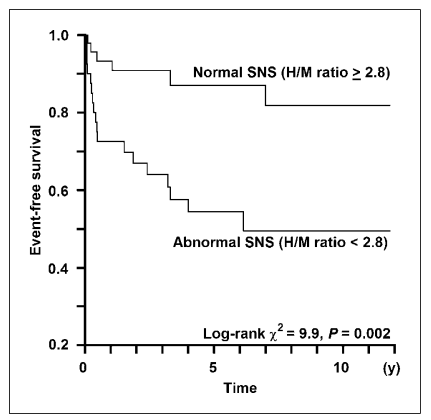




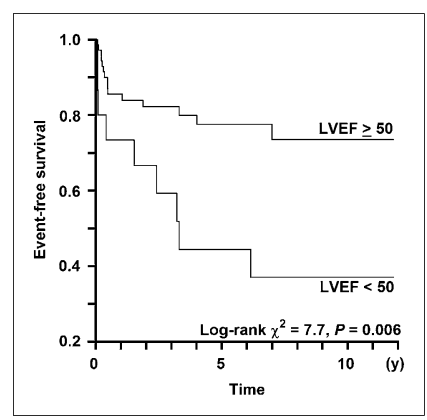

FIGURE 4. Kaplan-Meier survival curves of sudden cardiac death or ventricular tachyarrhythmic event-free survival according to left ventricular dysfunction (LVEF < $50 \%)$. Left ventricular dysfunction was predictive of sudden cardiac death or ventricular arrhythmic events.

model analysis, SNS abnormality remained independently predictive of sudden cardiac death or ventricular tachyarrhythmic events, with a hazard ratio of 3.6 (95\% confidence interval, $1.4-9.2 ; P=0.007$ ) after adjusting for age, sex, coronary risk factors, symptoms, LVEF, history of structural heart disease, and medication use. A combination of SNS abnormality and left ventricular dysfunction was a more powerful predictor of recurrent ventricular tachyarrhythmic events, with a hazard ratio of 4.4 (95\% confidence interval, 1.9-9.9; $P<0.0001$ ) after adjusting for potential confounding variables.

\section{DISCUSSION}

Our major finding was that SNS abnormality predicted sudden cardiac death or recurrent ventricular tachyarrhythmic events in patients with a history of ventricular tachyarrhythmia. Further, SNS abnormality had incremental and additive prognostic power when combined with left ventricular dysfunction.

\section{SNS Abnormality in Patients with a History of Ventricular Arrhythmia}

Since Schwartz et al. $(10,23)$ reported a direct association between autonomic dysfunction and a propensity toward VF

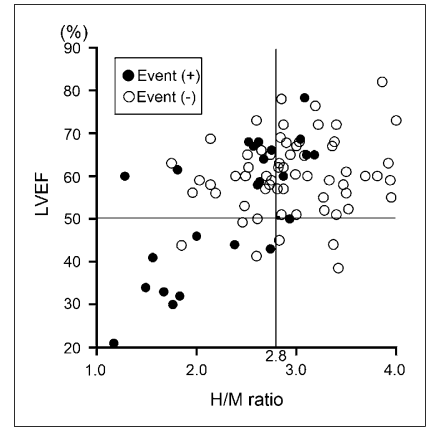

FIGURE 5. Relationship between cardiac SNS abnormality and left ventricular function in patients with history of ventricular arrhythmia. Closed circle indicates sudden cardiac death or ventricular tachyarrhythmic events, and open circle indicates no events during follow-up. Patients with both SNS abnormality $(\mathrm{H} / \mathrm{M}$ ratio $<$ 2.8) and left ventricular dysfunction (LVEF $<50 \%$ ) were more likely to have ventricular tachyarrhythmic events than were other patients (9/12 patients [75\%] vs. $15 / 74$ patients [20.3\%]).

during acute myocardial ischemia, a wealth of evidence has supported the widely held belief that SNS activity participates in the genesis of ventricular tachyarrhythmia and sudden cardiac death (24) because of potentially proarrhythmic electrophysiologic effects caused by catecholamine (25). Recently, SNS abnormality has been described for ventricular tachyarrhythmia associated with myocardial ischemia, infarction (26), dilated and hypertrophic cardiomyopathy (27), and heart failure (1). When compensatory support is needed to meet the demands of organ perfusion due to reduced myocardial contractility or hemodynamic overload by structural heart diseases, the cardiac adrenergic system becomes maladaptive and can cause the change that increases susceptibility to ventricular tachyarrhythmia (24). Kimura et al. (28) suggested that mechanical stretching or a pressure overload into the heart in various heart diseases not only causes sympathetic hyperinnervation but also results in rejuvenation (hyperplasia, reduced norepinephrine uptake, reduced norepinephrine synthesis, and fetal gene expression)

\section{TABLE 3. Prediction of Long-Term Prognosis According to Univariate Analysis}

\begin{tabular}{|c|c|c|c|c|c|}
\hline \multirow[b]{2}{*}{ Variable } & \multicolumn{2}{|c|}{$\begin{array}{l}\text { Sudden death or ventricular } \\
\text { arrhythmic events over } 11 \text { y } \\
\text { of follow-up }\end{array}$} & \multirow{2}{*}{$\begin{array}{l}\text { Hazard ratio, with } \\
\qquad 95 \% \mathrm{Cl}\end{array}$} & \multirow[b]{2}{*}{$\chi^{2}$} & \multirow[b]{2}{*}{$P$} \\
\hline & Present & Absent & & & \\
\hline $\mathrm{H} / \mathrm{M}$ ratio $<2.8$ & $18 / 40(45 \%)$ & $6 / 46(13 \%)$ & $4(1.6-10)$ & 8.5 & 0.004 \\
\hline LVEF $<50 \%$ & $9 / 15(60 \%)$ & $15 / 71(21.1 \%)$ & $1.6(1.3-7)$ & 6.9 & 0.008 \\
\hline $\mathrm{H} / \mathrm{M}$ ratio $<2.8$ and $\mathrm{LVEF}<50 \%$ & $9 / 12(75 \%)$ & $15 / 74(20.3 \%)$ & $4.4(1.9-9.9)$ & 12.1 & $<0.0001$ \\
\hline History of dilated cardiomyopathy & $7 / 11(63.6 \%)$ & $17 / 75(22.7 \%)$ & $2.8(1.2-6.8)$ & 5.3 & 0.021 \\
\hline History of structural heart disease & $11 / 23(47.8 \%)$ & $13 / 63(20.6 \%)$ & $2.3(1-5.2)$ & 4.3 & 0.038 \\
\hline Older age ( $\geq 65 y)$ & $5 / 18(27.8 \%)$ & $19 / 68(27.9 \%)$ & $1.0(0.4-2.6)$ & 0.09 & NS \\
\hline Male & $17 / 56(30.4 \%)$ & $7 / 30(23.3 \%)$ & $1.3(0.6-3.3)$ & 0.44 & NS \\
\hline History of ischemic heart disease & $1 / 7(14.3 \%)$ & $23 / 79(29.1 \%)$ & $2.2(0.3-16.4)$ & 0.6 & NS \\
\hline History of hypertrophic cardiomyopathy & $2 / 4(50 \%)$ & 22/82 (26.8\%) & $2.3(0.5-9.7)$ & 1.2 & NS \\
\hline History of genetic arrhythmogenic disorder & $4 / 9(44.4 \%)$ & $20 / 77(25.9 \%)$ & $2.2(0.7-6.4)$ & 2 & NS \\
\hline History of congenital heart disease & $4 / 7(57.1 \%)$ & $20 / 79(42.9 \%)$ & $2(0.7-6)$ & 1.7 & NS \\
\hline Use of $\beta$-blocker & $10 / 24(41.7 \%)$ & $14 / 62(22.6 \%)$ & $1.7(0.8-3.9)$ & 1.7 & NS \\
\hline
\end{tabular}


of SNS, which eventually leads to cardiac denervation. Those results support the close relationship between left ventricular function and SNS activity in patients with ventricular tachyarrhythmia. On the other hand, patients who underwent heart transplantation and had denervated hearts did not show severe left ventricular dysfunction, but about $10 \%$ of the patients experienced sudden cardiac death, presumably due to arrhythmia (29), suggesting a direct effect of SNS abnormality (30-32). In the present study, SNS abnormality increased the occurrence of recurrent ventricular arrhythmia independent of left ventricular dysfunction or structural heart disease. A more recent study (18) also reported that SNS abnormality was an independent predictor of arrhythmogenic mortality during $15 \mathrm{mo}$ in high-risk patients with ventricular tachyarrhythmia who included both patients with and patients without structural heart disease. Those results or ours suggest that SNS abnormality is more sensitive for predicting arrhythmic events than is left ventricular dysfunction or structural heart disease. Our results may support the possibility that SNS activity contributes to the fine control of cardiac performance on demand, but not cardiac function (30).

\section{SNS Abnormality and Left Ventricular Dysfunction for Long-Term Prognosis}

SNS activity correlates not only with LVEF but also with various markers of cardiac function: $\mathrm{x}$-ray cardiothoracic ratio (1), left ventricular end-diastolic diameter (1), QRS wave duration $(4,5,33)$, cardiac index (34), and plasma concentration of brain natriuretic peptide (35). Terai et al. (27) reported in 2003 that the occurrence of malignant VT is associated with SNS abnormality as measured by ${ }^{123}$ I-MIBG scintigraphy in patients with hypertrophic cardiomyopathy, but patients with VT had a significantly lower LVEF than did those without VT. On the other hand, Wakabayashi et al. (26) reported that a combination of cardiac function and SNS activity identified patients at increased risk of cardiac death unrelated to the underlying etiology of heart disease. Nagahara et al. (18) demonstrated that a combination of function and SNS abnormality is predictive of ICD discharge during 15 mo in high-risk patients with VT or VF who were diagnosed as being at high risk and who had an implanted ICD. In the present study, we showed in the random cardiac population with arrhythmic disorder that SNS abnormality had incremental and additive long-term prognostic power in combination with left ventricular dysfunction.

\section{Study Limitations}

Because our results are based on experience at a single center with patients referred because of a history of VT or VF, the more general applicability of our findings may be limited. The H/M ratio obtained in our study patients was higher than that obtained in other patients $(1,36)$. However, our study patients had $\mathrm{H} / \mathrm{M}$ ratios significantly lower than reference values (vs. $3.3 \pm 0.5, P<0.0005$ ). The variability in MIBG distribution is well known, and there are significant variations in $\mathrm{H} / \mathrm{M}$ ratios from one nuclear medicine center to another in both patients with and patients without heart disease.

We investigated SNS abnormality as a predictor of sudden cardiac death in a limited number of patients, with low event rates. However, many prognostic studies using ${ }^{123}$ I-MIBG scintigraphy have also been evaluated in small samples (17). In the present study, the 86 reported patients were well characterized, were followed for a long period, and may therefore be accepted as a relatively large cohort given the rarity of the disease.

The diagnostic accuracy for predicting recurrent ventricular tachyarrhythmic events using ${ }^{123}$ I-MIBG scintigraphy was not so high in our low-risk patients (75\% sensitivity, $64.5 \%$ specificity, $45 \%$ positive predictive value, and $87 \%$ negative predictive value) as that using $\mathrm{T}$ wave alternans in high-risk patients with severe left ventricular dysfunction (LVEF < $30 \%$ ) (37). Furthermore, the diagnostic accuracy was lower in our study patients with an LVEF of greater than 50\% $(60 \%$ sensitivity and 66\% specificity) than in those with an LVEF of $50 \%$ or less. $\mathrm{T}$ wave alternans is also known to decrease diagnostic accuracy in patients with random cardiac diseases who are at relatively low risk (38). Lower sensitivity and a relatively wide range of hazard ratios may result from a lower event ratio in low-risk patients. However, our results indicate the importance of SNS abnormality for risk management in the random cardiac population, including low-risk patients, rather than the significance of SNS activity as a discriminator of type of ventricular tachyarrhythmia, such as VT and VF.

Sex, a history of hypertension, congestive heart failure, VF, and the disuse of antiarrhythmic drugs are generally considered incremental predictors of sudden cardiac death or recurrent ventricular tachyarrhythmic events. However, these variables were not predictive of this endpoint in the current studies, which were evaluated not only in a small sample using ${ }^{123}$ I-MIBG scintigraphy $(18,26)$ but also in a large sample at relatively low risk (38). Our results would also be influenced by similar causes.

\section{CONCLUSION}

SNS abnormality predicted recurrent ventricular tachyarrhythmic events. The evaluation of SNS abnormality using ${ }^{123}$ I-MIBG scintigraphy may be an option for screening patients at high risk for sudden cardiac death.

\section{ACKNOWLEDGMENTS}

We thank the medical, technical, and laboratory staffs; Drs. Jyunpei Suyama and Noritaka Seino of the Service of Nuclear Medicine; and Drs. Yoshino Minoura and Tatsuya Onuki of the Arrhythmic Laboratory of Showa University Hospitals, who actively participated in data collection.

\section{REFERENCES}

1. Merlet P, Valette H, Dubois-Randé JL, et al. Prognostic value of cardiac metaiodobenzylguanidine imaging in patients with heart failure. J Nucl Med. 1992;33:471-477. 
2. Watanabe J, Thamilarasan M, Blackstone EH, Thomas JD, Lauer MS. Heart rate recovery immediately after treadmill exercise and left ventricular systolic dysfunction as predictors of mortality: the case of stress echocardiography. Circulation. 2001;104:1911-1916.

3. Gregoratos G, Abrams J, Epstein AE, et al. ACC/AHA/NASPE 2002 guideline update for implantation of cardiac pacemakers and antiarrhythmia devices: summary article-a report of the American College of Cardiology/American Heart Association task force on practice guidelines (ACC/AHA/NASPE committee to update the 1998 pacemaker guidelines). J Am Coll Cardiol. 2002;40:1703-1719.

4. Bloomfield DM, Steinman RC, Namerow PB, et al. Microvolt T-wave alternans distinguishes between patients likely and patients not likely to benefit from implanted cardiac defibrillator therapy: a solution to the multicenter automatic defibrillator implantation trial (MADIT) II conundrum. Circulation. 2004;110:1885-1889.

5. Reynolds MR, Josephson ME. MADIT II (second multicenter automated defibrillator implantation trial) debate: risk stratification, costs, and public policy. Circulation. 2003;108:1779-1783.

6. ACC/AHA/ESC 2006 guidelines for management of patients with ventricular arrhythmias and the prevention of sudden cardiac death: a report of the American College of Cardiology/American Heart Association task force and the European Society of Cardiology Committee for Practice Guidelines (writing committee to develop guidelines for management of patients with ventricular arrhythmias and the prevention of sudden cardiac death)_developed in collaboration with the European Heart Rhythm Association and the Heart Rhythm Society. J Am Coll Cardiol. 2006;48:e247-e346.

7. Hofmann T, Meinertz T, Kasper W, et al. Mode of death in idiopathic dilated cardiomyopathy: a multivariate analysis of prognostic determinants. Am Heart J. 1988;116:1455-1463.

8. Survivors of out-of-hospital cardiac arrest with apparently normal heart: need for definition and standardized clinical evaluation-consensus statement of the joint steering committees of the unexplained cardiac arrest registry of Europe and of the idiopathic ventricular fibrillation registry of the United States. Circulation. 1997;95:265-272.

9. Wichter T, Breithardt G, Borggrefe M. Ventricular tachycardia in the normal heart. In: Pordrin PJ, Kowery PR, eds. Cardiac Arrhythmia: Mechanism, Diagnosis and Management. Baltimore, MD: Williams and Wilkins; 1995:1219-1238.

10. Billman GE, Schwartz PJ, Stone HL. Baroreceptor reflex control of heart rate: a predictor of sudden death. Circulation. 1982;66:874-880.

11. Jouven X, Empana J, Schwartz PJ, Desnos M, Courbon D, Ducimetiere P. Heart-rate profile during exercise as a predictor of sudden death. N Engl J Med. 2005;352: 1951-1958.

12. La Rovere MT, Pinna GD, Hohnloser SH, et al., for the ATRAMI Investigators. Autonomic tone and reflexes after myocardial infarction: baroreflex sensitivity and heart rate variability in the identification of patients at risk for life-threatening arrhythmias-implications for clinical trials. Circulation. 2001;103:2072-2077.

13. Mitrani RD, Klein LS, Miles WM, et al. Regional cardiac sympathetic denervation in patients with ventricular tachycardia in the absence of coronary artery disease. J Am Coll Cardiol. 1993;22:1344-1353.

14. Schafers M, Wichter T, Lerch H, et al. Cardiac ${ }^{123}$ I-MIBG uptake in idiopathic ventricular tachycardia and fibrillation. J Nucl Med. 1999;40:1-5.

15. Gohl K, Feistel H, Weikl A, Bachmann K, Wolf F. Congenital myocardial sympathetic dysinnervation (CMSD): a structural defect of idiopathic long QT syndrome. Pacing Clin Electrophysiol. 1991;14:1544-1553.

16. Wichter T, Matheja P, Eckardt L, et al. Cardiac autonomic dysfunction in Brugada syndrome. Circulation. 2002;105:702-706.

17. Paul M, Schafers M, Kies $P$, et al. Impact of sympathetic innervation on recurrent life-threatening arrhythmias in the follow-up of patients with idiopathic ventricular fibrillation. Eur J Nucl Med Mol Imaging. 2006;33:866-870.
18. Nagahara D, Nakata T, Hashimoto A, et al. Predicting the need for an implantable cardioverter defibrillator using cardiac metaiodobenzylguanidine activity together with plasma natriuretic peptide concentration or left ventricular function. J Nucl Med. 2008;49:225-233.

19. Yamashina S, Yamazaki J. Neuronal imaging using SPECT. Eur J Nucl Med Mol Imaging. 2007;34:939-950.

20. Sharir T, Germano G, Kavanagh PB, et al. Incremental prognostic value of poststress left ventricular ejection fraction and volume by gated myocardial perfusion single photon emission tomography. Circulation. 1999;100:1035-1042.

21. Kaplan E, Meier P. Nonparametric estimation from incomplete observations. J Am Stat Soc. 1958;53:457-481.

22. Cox D. Regression models and life tables. J R Stat Soc B. 1972;34:187-220.

23. Schwartz PJ, Vanoli E, Stramba-Badiale M, De Ferrari GM, Billman GE, Foreman RD. Autonomic mechanism and sudden death. Circulation. 1988;78: 969-979.

24. Anderson KP. Sympathetic nervous system activity and ventricular tachyarrhythmias: recent advances. Ann Noninvasive Electrocardiol. 2003;8:75-89.

25. Corr PB, Yamada KA, Witkowski FX. Mechanisms controlling cardiac autonomic function and their relationship to arrhythmogenesis. In: Fozzard HA, Jennings RB, Haber E, Katz AM, Morgen HE, eds. The Heart and Cardiovascular System. Raven, NY: Scientific Foundations; 1986:1343-1403.

26. Wakabayashi $T$, Nakata $T$, Hashimoto $A$, et al. Assessment of underlying etiology and cardiac sympathetic innervation to identify patients at high risk of cardiac death. J Nucl Med. 2001;42:1757-1767.

27. Terai $\mathrm{H}$, Shimizu M, Ino $\mathrm{H}$, et al. Cardiac sympathetic nerve activity in patients with hypertrophic cardiomyopathy with malignant ventricular tachyarrhythmias. J Nucl Cardiol. 2003;10:304-310.

28. Kimura K, Ieda M, Kanazawa $\mathrm{H}$, et al. Cardiac sympathetic rejuvenation: a link between nerve function and cardiac hypertrophy. Circ Res. 2007;100: 1755-1764.

29. Chantranuwat C, Blakey JD, Kobashigawa JA, et al. Sudden, unexpected death in cardiac transplant recipients: an autopsy study. J Heart Lung Transplant. 2004; 23:683-689.

30. Ieda M, Kanazawa H, Kimura K, et al. Sema3a maintains normal heart rhythm through sympathetic innervation patterning. Nat Med. 2007;13:604-612.

31. Kienzle MG, Martins JB, Constantin L, Aschoff A. Effect of direct, reflex and exercise-provoked increases in sympathetic tone on idiopathic ventricular tachycardia. Am J Cardiol. 1992;69:1433-1438.

32. Zipes DP. Sympathetic stimulation and arrhythmias. N Engl J Med. 1991;325: 656-657.

33. Baldasseroni S, Opasich C, Gorini M, et al. Left bundle-branch block is associated with increased 1-year sudden and total mortality rate in 5517 outpatients with congestive heart failure: a report from the Italian Network on Congestive Heart Failure. Am Heart J. 2002;143:398-405.

34. Imamura Y, Ando H, Ashihara T, Fukuyama T. Myocardial adrenergic nervous activity is intensified in patients with heart failure without left ventricular volume or pressure overload. J Am Coll Cardiol. 1996;28:371-375.

35. Kyuma M, Nakata T, Hashimoto A, et al. Incremental prognostic implications of brain natriuretic peptide, cardiac sympathetic nerve innervation, and noncardiac disorders in patients with heart failure. J Nucl Med. 2004;45:155-163.

36. Merlet P, Benvenuti C, Moyse D, et al. Prognostic value of MIBG imaging in idiopathic dilated cardiomyopathy. J Nucl Med. 1999;40:917-923.

37. Narayan SM. T-wave alternans and the susceptibility to ventricular arrhythmias. J Am Coll Cardiol. 2006;47:269-281.

38. Nieminen T, Leftimaki T, Viik J, et al. T-wave alternans predicts mortality in a population undergoing a clinically indicated exercise test. Eur Heart J. 2007;28:2332-2337. 